\title{
Magnetron Sputter Deposition of Zirconium-Silicide Coating for Mitigating High Temperature Oxidation of Zirconium-Alloy
}

\author{
Hwasung Yeom ${ }^{\mathrm{a}}$, Benjamin Maier ${ }^{\mathrm{a}}$, Robert Mariani ${ }^{\mathrm{b}}$, David Bai ${ }^{\mathrm{b}}$, Steven Fronek ${ }^{\mathrm{a}}$, Peng $^{\mathrm{X}} \mathrm{u}^{\mathrm{c}}$, and \\ Kumar Sridharan ${ }^{\mathrm{a},{ }^{*}}$ \\ ${ }^{a}$ Department of Engineering Physics, University of Wisconsin-Madison, Madison, Wisconsin \\ 53706, USA \\ ${ }^{\mathrm{b}}$ Idaho National Laboratory, Idaho Falls, Idaho 83402, USA \\ ${ }^{c}$ Westinghouse Electric Company, Columbia, SC 29061, USA
}

Address correspondence to Professor Kumar Sridharan

Engineering Physics Department, 1500 Engineering Drive Rm. 919, University of Wisconsin, Madison WI 53706, USA.

E-mail: ksridhar@wisc.edu, Phone number: 1 (608) 263-4789; Fax number: 1 (608) 263-7451 


\begin{abstract}
The air oxidation behavior of zirconium-silicide coatings for three stoichiometries, namely, $\mathrm{Zr}_{2} \mathrm{Si}$, $\mathrm{ZrSi}$, and $\mathrm{ZrSi}_{2}$, at $700{ }^{\circ} \mathrm{C}$ has been investigated. These three coatings were deposited on a zirconium-alloy substrate using a magnetron sputter process at a low temperature. Argon gas pressure was observed to have a profound effect on the coating microstructure, with lower pressures favoring a denser and more protective microstructure. Coatings of $\mathrm{ZrSi}_{2}$ stoichiometry clearly showed superior oxidation resistance presumably due to the formation of a thin protective oxide layer, consisting of nanocrystalline $\mathrm{SiO}_{2}$ and $\mathrm{ZrSiO}_{4}$ in amorphous $\mathrm{Zr}-\mathrm{Si}-\mathrm{O}$ matrix. The thermal stability of the coatings was evaluated by annealing in an argon environment, and this also assisted in eliciting the effects of oxidation-induced inward Si migration. Thicker coatings of $\mathrm{ZrSi}_{2}$ were prepared and evaluated for oxidation resistance at $700{ }^{\circ} \mathrm{C}$ for longer exposure times, as well as at $1000^{\circ} \mathrm{C}$ and $1200^{\circ} \mathrm{C}$. Once again the thin oxide layer provided for significant oxidation resistance. Pre-oxidizing the samples at $700{ }^{\circ} \mathrm{C}$ prior to $1000{ }^{\circ} \mathrm{C}$ and $1200{ }^{\circ} \mathrm{C}$ oxidation tests substantially reduced the extent of oxidation. Insights into the fundamental mechanisms of the oxidation behavior of zirconium-silicide coatings were obtained using a combination of scanning electron microscopy, x-ray diffraction, and x-ray photoelectron spectroscopy techniques. One potential application of these coatings is to enhance the oxidation resistance of zirconium-alloy fuel cladding in light water reactors under normal and accident conditions.
\end{abstract}




\section{KEYWORDS}

Zirconium-Silicide

Magnetron Sputter Deposition

High Temperature Oxidation

Zirconium alloy 


\section{Introduction}

Coatings of structural material for elevated temperature applications are becoming increasingly important in a broad spectrum of industries including, aerospace, power generation, and chemical plants. In particular, long term exposure of base materials in high temperature air environment undermines inherent mechanical properties by chemical reaction with ambient oxygen and moisture. For example, the exothermic reaction of zirconium-alloy and high temperature air or steam in high temperature leads to loss of intrinsic mechanical properties due to thick oxide layer formation and hydrogen embrittlement. [1-3] Transition metal silicides, particularly molybdenum-silicide $\left(\mathrm{MoSi}_{2}\right)$ have been extensively used as coatings for graphite, Molybdenum, and Niobium structural material in the high temperature applications due to its excellent oxidation resistance and mechanical properties [4-6]. However, there is very limited literature on zirconium-silicide in regards to oxidation or in its use as a coating material. Zirconium silicides $\left(\mathrm{Zr}_{\mathrm{x}} \mathrm{Si}_{\mathrm{y}}\right)$ have high melting points (e.g., $\mathrm{ZrSi}$ and $\mathrm{Zr}_{3} \mathrm{Si}_{2}$ melts at $2203{ }^{\circ} \mathrm{C}$ and $2215^{\circ} \mathrm{C}$, respectively [7]). In high temperature air, formation of a passive oxide layer, outstanding oxidation resistance $\mathrm{SiO}_{2}$ and $\mathrm{ZrSiO}_{4}$, suggest that zirconium-silicide could be good candidate oxidation resistant coating material for high temperature applications. [8,9] In particular, the application of zirconium-silicide coatings on zirconium alloys appears logical given the inherent compatibility between the coating and substrate materials, and no previous studies have been reported on the oxidation behavior of this particular coating-substrate system.

In this study, magnetron sputter deposition of zirconium-silicide on Zircaloy-4 substrate has been explored. To maximize oxidation resistance, deposition parameters and coating compositions have been investigated with characterization of oxidation behavior at $700{ }^{\circ} \mathrm{C}$ in air and of thermal stability at $700{ }^{\circ} \mathrm{C}$ in argon environment. A temperature of $700{ }^{\circ} \mathrm{C}$ was selected to 
avoid excessive substrate oxidation and to evaluate a formation of non-protective oxide scale like $\mathrm{MoSi}_{2}$. [4,10] Finally, the optimized zirconium-silicide coating was prepared and oxidized at $1000{ }^{\circ} \mathrm{C}$ and $1200{ }^{\circ} \mathrm{C}$ in ambient air to evaluate oxidation resistance, which demonstrates potential feasibility of the zirconium-silicide coating for zirconium-alloy cladding in light water reactors under potential accident scenarios.

\section{Experimental Procedure}

Test flat coupons of Zircaloy-4 (referred to henceforth as Zirc-4, nominal composition: 0.07 wt.\% Cr, 0.18 wt.\% Fe, 0.09 wt.\% O, and balanced Zr) substrates for deposition of zirconiumsilicide coatings were prepared by sectioning square samples $12.7 \times 12.7 \mathrm{~mm}^{2}, 2.8 \mathrm{~mm}$ thick in dimensions. The samples were then ground successively with 320 grit and 600 grit SiC abrasive paper followed by cleaning with acetone and methanol. Three compositions of zirconium-silicide sputter targets (i.e., $\mathrm{Zr}_{2} \mathrm{Si}, \mathrm{ZrSi}$, and $\mathrm{ZrSi}_{2}$ ) were procured from a commercial vendor. The sputter targets were $76 \mathrm{~mm}$ in diameter and $3.2 \mathrm{~mm}$ in thickness. The targets were of $99.5 \%$ nominal purity and with $3.2 \mathrm{~mm}$ thick copper backing plates for enhancing thermal conductivity during the deposition process.

Prior to initiating the coating deposition process in the magnetron sputter system, the substrates were subjected to in-situ plasma cleaning (dc 500W for 5 minutes under 1.6 Pa argon pressure) to remove any residual surface contamination and native oxide layer on the surface of the substrate. Zirconium-silicide coating deposition was performed using a base pressure of $2.6 \mathrm{x}$ $10^{-4} \mathrm{~Pa}$. Argon sputter gas pressures were $0.53 \mathrm{~Pa}$ and $1.33 \mathrm{~Pa}$ with a flow rate of $20 \mathrm{sccm}-$ these parameters were selected based on previous studies of magnetron sputter deposited coatings for high-temperature oxidation resistance. [11,12] DC sputter power was $138 \mathrm{~W}$. The distance between the sputter target and the sample stage was $150 \mathrm{~mm}$ and the sample stage was rotated at 
$10 \mathrm{rpm}$ during the deposition to achieve improved uniformity of the coating. The deposition was performed at $19{ }^{\circ} \mathrm{C}$, as monitored in situ by thermocouples, in order to avoid any phase transformations and thermal stresses in the coatings. In order to investigate the effect of argon pressure and composition of coating on oxidation resistance, the depositions were performed under conditions listed in Table 1. The coating deposition for a single step took 150 minutes, and six steps were performed to achieve thicker coatings that were also investigated in this study. For this multiple step deposition, a plasma cleaning step was employed between the steps to remove any contamination due to interruptions in the coating process. In addition to Zirc-4 substrates, the coatings were also deposited on plasma cleaned $\mathrm{Si}$ (100) wafers, which were used for measuring film thickness and observing coating cross-sectional microstructure.

Isothermal oxidation tests were performed at elevated temperatures in a commercial furnace (e.g., Lindberg box furnace, model\#51442). Initial studies involved oxidation tests at $700{ }^{\circ} \mathrm{C}$ in ambient air for exposure durations of up to 5 hours, with samples being removed each hour for weight change measurements (as an initial measure of the extent of oxidation) performed with Satorius micro-precision balance (model\#CPA26P) with $0.002 \mathrm{mg}$ resolution. Annealing of the coatings was carried out in argon environment to understand high temperature stability, which then was used to optimize the multi-step thicker coatings. For this, the samples were encapsulated in argon back-filled quartz tube along with pure zirconium granules to reduce residual oxygen gas during annealing. The thicker coatings produced by multiple tests were tested for oxidation at $700{ }^{\circ} \mathrm{C}$ for 20 hours, at $1000{ }^{\circ} \mathrm{C}$ for 1 hour, and $1200{ }^{\circ} \mathrm{C}$ for 10 minutes. Table 1 summarizes the salient features of this experimental study. 
Surface morphologies and cross sectional microstructure of the as-deposited, oxidized, and annealed zirconium-silicide coatings were characterized by Zeiss LEO Scanning Electron Microscope (SEM) in conjunction with Energy Dispersive Analysis System (EDS). Phase identification of the coatings was conducted using Bruker D8 Discovery x-ray diffraction (XRD) system with $\mathrm{Cu} \mathrm{K} \alpha$ radiation. Diffraction peaks were acquired from $30^{\circ}$ to $90^{\circ}$ with coupled $2 \theta$ mode and from $30^{\circ}$ to $50^{\circ}$ in $2 \theta$ with a $2^{\circ}$ grazing incident beam. To identify phases in the asdeposited coatings, thin foils of the coatings were prepared by a Zeiss Auriga Focus Ion Beam milling and imaged with a Tecnai 12 Transmission Electron Microscope (TEM). Very nearsurface composition and chemical bonding of phases was evaluated by Thermo-Scientific Ka Xray Photoemission Spectroscopy (XPS). Prior to the binding energy acquisition, surface cleaning was performed by $3 \mathrm{keV}$ Ar ion source for 30 seconds under high vacuum to remove any residual surface contamination.

\section{Results and Discussion}

\subsection{As-deposited Thin Coatings}

Elemental composition of the very near surface of the as-deposited coatings, as analyzed by the XPS, was consistent in trend with the corresponding target chemistry. Argon gas pressure during the process did not influence the coating composition. Grazing incident XRD patterns showed only peaks corresponding to zirconium from the underlying substrate and no peaks corresponding to the coatings was observed for any of the coating stoichiometries (Fig. 1).

Surface morphology and cross sectional microstructure of the coatings, were investigated using SEM. The coatings showed uniform and smooth surface with no indication of spallation. No noticeable differences in surface topography and microstructure were identified in coatings 
deposited using the different target compositions. On the other hand, argon gas pressure influenced microstructure significantly as shown for example for $\mathrm{ZrSi}_{2}$ in Fig. 2. The $\mathrm{ZrSi}_{2} \# 1$ coating deposited at higher argon pressure (i.e., 1.33 Pa) exhibited relatively rougher surface and showed nanometer scale gaps in the microstructure (Fig. 2a). Cross-sectional fracture surfaces of these coatings deposited on Si substrate showed tapered columnar microstructures which are revealed more clearly in Fig. 2c. In contrast, the lower argon pressure (i.e., $0.53 \mathrm{~Pa}$ ), $\mathrm{ZrSi}_{2} \# 2$ coating, exhibited short and dense columnar structures with smoother surface, which are shown in Fig. $2 b$ and $2 d$. The observation is in good agreement with Thornton's model $[13,14]$ suggesting that the columnar tapered morphology of the films is a result of atomic shadowing and a low mobility of sputtered atoms on the growing surface at low temperatures. In addition, this morphology would be promoted by increased scattering between argon atoms and target atoms at higher argon pressures. It is expected that the nanoscale gaps between the long columnar structures at the higher argon pressure may act as paths for the transport of oxygen to the underlying Zirc-4 substrate during the oxidation tests.

The microstructures of the as-deposited coatings were additionally investigated by TEM. The cross-sectional bright field TEM image (Fig. 3a) for the as-deposited $\mathrm{ZrSi}_{2} \# 2$ coating displayed a columnar structure defined by the voided boundaries aligned with the film growth direction, but no clear contrast was observed between the grains. Selected area diffraction (SAD) pattern (Fig. 3b) for the corresponding area exhibited diffused halos with fuzzy rings. No distinct diffraction spots characteristic of crystalline phases was observed. Based on XRD patterns and the TEM$\mathrm{SAD}$ analysis, it is speculated that the as-deposited zirconium-silicide coatings are likely amorphous or small volume fraction of nanocrystalline phases in an amorphous matrix. High 
resolution TEM (HRTEM) images will be required for further analysis of the structure of the asdeposted coatings.

The coating composition, phase content, microstructure, and thickness are summarized in Table 2 .

\subsection{Oxidation of Thin Coatings}

The thin coatings at lower pressure $\left(\mathrm{Zr}_{2} \mathrm{Si} \# 2\right.$, $\mathrm{ZrSi} \# 2$, and $\left.\mathrm{ZrSi}_{2} \# 2\right)$ deposited on Zirc-4 coupons were oxidized at $700{ }^{\circ} \mathrm{C}$ for 5 hours in ambient air to evaluate their oxidation resistance as a function of coating stoichiometries. Fig. 4 shows the weight changes (per unit area of the sample) of the coatings of the three stoichiometries and uncoated Zirc-4 at each hour of oxidation. Rapid uptake of oxygen was identified for all the samples during the first hour of exposure, followed by relatively moderate oxidation rate, an effect which is associated with formation of passive oxide layer during the initial exposure, resulting in a self-limiting oxidation behavior. All the coatings revealed smaller weight gain compared to the bare Zirc-4. In particular, the coating with highest $\mathrm{Si}$ content (i.e., $\mathrm{ZrSi}_{2} \# 2$ ) displayed the lowest weight gain (about $60 \%$ compared to the bare Zirc-4). Since only the two major surfaces of the substrates were primarily coated, the weight gain results underestimate the actual improvements in oxidation resistance of the coatings. Therefore, observation of oxide layer thickness by cross-sectional SEM images was deemed to be a more realistic assessment of the improvements in oxidation behavior due to the coatings.

The thickness of oxide layer of the coatings was measured by cross-sectional SEM images (Fig. 5), and the trends were in good agreement with the weight gain results. Significant oxide layer $(13-15 \mu \mathrm{m})$ developed underneath the $\mathrm{Zr}_{2} \mathrm{Si} \# 2$ coating due to permeation of oxygen 
through the coating and its diffusion into the underlying Zirc-4 substrate. The ZrSi\#2 coating appeared to form a thinner zirconium oxide in the underlying Zirc-4 alloy substrate. However, no oxide layer was observed in the underlying Zirc-4 alloy substrate for the $\mathrm{ZrSi}_{2} \# 2$ coating. The high magnification images of the oxide scales (Fig. 5d-5f) revealed local variation of composition in the thin coatings and substrate. In the upper region of the $\mathrm{Zr}_{2} \mathrm{Si} \# 2$ and the $\mathrm{ZrSi} \# 2$ coatings, zirconium-rich oxide was identified by EDS analysis (the brighter regions in Fig. 5d and 5e), which also contained microcracks which would allow for oxygen permeation to the underlying substrate. However, the oxidized $\mathrm{ZrSi}_{2} \# 2$ coating did not show the zirconium-rich oxide in the coating but instead revealed homogenous microstructure. In addition, for the $\mathrm{ZrSi}_{2} \# 2$ coating, silicon diffusion from the coating to the substrate was clearly detected which may promote coating-substrate adhesion between the coating and the substrate. The Si diffusion depth was about $590 \mathrm{~nm}$, and the composition of this region was predominantly $\mathrm{ZrSi}$.

The near-surface chemical composition of the oxidized coatings was analyzed by XPS (signal acquired over a $400 \mu \mathrm{m}$ diameter circular region) and compositional data is summarized in the Table 3. In all cases the near-surface region showed an enhanced Zr:Si ratio indicating a high inward mobility of silicon in the oxide scale at elevated temperatures.

The binding energy spectrum for $\mathrm{O} 1 \mathrm{~s}$ in each coating after the oxidation is shown in Fig. 6. The peak binding energy increased with increasing silicon concentration in the coating, which means that characteristics of chemical bonds associated with oxygen were different depending on coating composition. To provide better understanding of the binding energy shift, deconvolution of O1s binding energy for the oxidized coatings was performed via commercial software (Origin 2015). First, the possible binding energy spectrum was assumed to be from three types of potential oxides with Gaussian distribution. The peak energies of these oxides were taken from 
literature to be, $531.8 \mathrm{eV}\left(\mathrm{ZrSiO}_{4}\right)$ [15], $532.4 \mathrm{eV}\left(\mathrm{SiO}_{2}\right)$ [16], and $530.5 \mathrm{eV}\left(\mathrm{ZrO}_{2}\right)[15,17]$. The intensity and FWHM for the components were arbitrarily chosen and iteration using the software was conducted up to the minimum residue between the sum of the estimated oxide spectra and the measured O1s binding energy curve. The deconvolution results indicate the intensity of each oxide component strongly depends on concentration of silicon or zirconium in the coating. The major oxide phase for the zirconium-rich coating (i.e., $\mathrm{Zr}_{2} \mathrm{Si \# 2}$ ) was $\mathrm{ZrO}_{2}$ with minor $\mathrm{ZrSiO}_{4}$ but that for the silicon-rich coating (i.e., $\mathrm{ZrSi}_{2} \# 2$ ) was $\mathrm{SiO}_{2}$ with minor $\mathrm{ZrSiO}_{4}$. The oxidized $\mathrm{ZrSi} \# 2$ coating showed strong $\mathrm{ZrSiO}_{4}$ peak with weak $\mathrm{ZrO}_{2}$ and $\mathrm{SiO}_{2}$ peaks. The XPS data for the coatings are in good agreement with the pseudo-binary $\mathrm{ZrO}_{2}-\mathrm{SiO}_{2}$ phase diagram. [18] Theoretically, $\mathrm{ZrSiO}_{4}$ is the only single stable phase in $\mathrm{ZrSi}$ oxidation but compositional alteration (see Fig.5e) due to the high mobility of silicon may result in $\mathrm{ZrO}_{2}$ and $\mathrm{SiO}_{2}$ formation by modulation of activities of zirconium and silicon. In addition, it is speculated that $\mathrm{ZrO}_{2}$ formation in the coating is one factor that undermines oxidation resistance of the zirconiumsilicide coating at elevated temperatures. The weight gain and oxide layer underneath the coatings are proportional to the intensity of $\mathrm{ZrO}_{2}$ spectrum in the oxidized coating. This is because of relatively higher oxygen transport rate for $\mathrm{ZrO}_{2}$ through grain boundaries [19] and crack formation in zirconium-rich oxide. However, very low oxygen permeation in $\mathrm{SiO}_{2}$ [20] and excellent corrosion resistance of $\mathrm{ZrSiO}_{4}[21]$ appeared to be very beneficial in preventing oxygen permeation to underlying Zirc-4 alloy substrate in high temperature air environment.

Oxidation of the coatings deposited at 1.33 Pa showed larger weight gain and thicker oxide layer than those deposited at $0.53 \mathrm{~Pa}$ due to the nanometer scale gaps in the columnar microstructure discussed earlier in Fig. 2. For example, $\mathrm{ZrSi}_{2} \# 2$ coating had approximately 59\% 
smaller weight gain compared to $\mathrm{ZrSi}_{2} \# 1$ at $700{ }^{\circ} \mathrm{C}$ for the 5-hour oxidation test. The studies on these higher Ar gas pressure coatings are not discussed further in this paper.

\subsection{Phase Stability of Thin Coatings}

One of key properties of an oxidation resistant coating is its thermodynamic stability at elevated temperatures [22]. For example, thermal exposure could lead to undesired phase formation in a coating or detrimental chemical interaction between a coating and the substrate. To elucidate the phase stability of zirconium-silicide coatings on Zirc-4 alloy substrate at high temperatures, the thin coatings discussed in the previous section were annealed at $700{ }^{\circ} \mathrm{C}$ for 5 hours in an argon environment. High magnification cross-sectional SEM images and zirconiumto-silicon ratio determined by EDS analysis for the coatings $\left(\mathrm{Zr}_{2} \mathrm{Si} \# 2\right.$, $\mathrm{ZrSi} \# 2$, and $\left.\mathrm{ZrSi}_{2} \# 2\right)$ after the annealing are shown in Fig. 7.

The $\mathrm{Zr}_{2} \mathrm{Si}$ coating showed a local variation of composition but reactivity with the substrate was not distinctively identified based on the SEM image and EDS analysis (Fig. 7a). A decrease in zirconium-to-silicon ratio in the middle of the $\mathrm{Zr}_{2} \mathrm{Si}$ coating (indicated by the cross mark in Fig. 7a) was observed. It is believed that residual oxygen inside the quartz capsule reacted with the surface of the $\mathrm{Zr}_{2} \mathrm{Si}$ coating, followed by the formation of $\mathrm{Zr}$-rich oxide on the surface. Thus, silicon atoms on the surface diffused inward and increased the Si concentration, however this diffusion was not far enough to reach the substrate. The SEM image of the annealed ZrSi coating displays a thin silicon-rich dark line arising from oxidation-induced silicon diffusion from the surface and silicon diffusion zone in the substrate (Fig. 7b). It is worth noting that a network of micron-scale cracks in the annealed $\mathrm{Zr}_{2} \mathrm{Si}$ and $\mathrm{ZrSi}$ coatings was observed as shown in Fig. 7c. The cracks appeared to initiate from conical-shaped defects which propagated to the substrate. It is expected that oxygen would readily permeate the coating through the open gap around these 
defects at elevated temperatures, resulting in reduced oxidation resistance. The annealed $\mathrm{ZrSi}_{2}$ coating showed silicon diffusion to the substrate similar to the oxidized $\mathrm{ZrSi}_{2}$ coating discussed earlier but the diffusion depth was smaller $(\sim 310 \mathrm{~nm})$ than the air-oxidized samples $(\sim 590 \mathrm{~nm})$, indicating that surface oxidation also drives Si inward towards to the coating-substrate interface. One plausible explanation is that oxidation generates additional unbound silicon atoms in oxide scale, which is supported by a previous study [8] - bulk $\mathrm{ZrSi}_{2}$ oxidation at $700{ }^{\circ} \mathrm{C}$ in ambient air produced a solid state mixture $\mathrm{Zr}-\mathrm{Si}-\mathrm{O}$ and a silicon phase. The newly released free silicon atoms showed a high diffusivity, and were associated with evolution of complex microstructures. In addition, XRD analysis for the annealed coatings showed not only strong zirconium peaks from the substrate but also weak zirconium-silicide peaks, indicating initiation of crystallization of the coatings.

In summary, the annealing experiments confirmed compositional alteration of zirconiumsilicide coatings $\left(\mathrm{Zr}_{2} \mathrm{Si}, \mathrm{ZrSi}\right.$, and $\left.\mathrm{ZrSi}_{2}\right)$ on $\mathrm{Zirc}-4$ substrate at $700{ }^{\circ} \mathrm{C}$ mainly due to the mobility of silicon atoms in the coatings followed by the reaction with the substrate.

\subsection{Oxidation Resistance of Optimized $\mathrm{ZrSi}_{2}$ Coatings}

Based on the oxidation and annealing of the thin zirconium-silicide coatings at $700{ }^{\circ} \mathrm{C}$ for 5 hours discussed above, silicon-rich zirconium-silicide stoichiometry, $\mathrm{ZrSi}_{2}$, was selected as a potential oxidation resistant coating for Zirc-4. For this next phase of the study, a thicker optimized zirconium-silicide coating $\left(\mathrm{ZrSi}_{2} \# 3\right)$ was prepared by six deposition steps under 0.53 Ar pressure.

A cross-sectional SEM in-lens image for the optimized coating is shown in Fig. 8a. The coating thickness was approximately $3.9 \mu \mathrm{m}$. The coating displayed dense and columnar 
microstructure similar to those observed in the thin $\mathrm{ZrSi}_{2}$ coatings (Fig. 2d) and the interface between each deposition step was revealed as the faint horizontal lines. No spallation or cracks were identified. To evaluate oxidation resistance of the optimized coating, three oxidation experiments were conducted: 1) $700{ }^{\circ} \mathrm{C}$ for 20 hours, 2) $1000{ }^{\circ} \mathrm{C}$ for 1 hour, and 3) $1200{ }^{\circ} \mathrm{C}$ for 10 minutes.

The longer oxidation for the coating at $700{ }^{\circ} \mathrm{C}$ enabled us to better understand oxide scale growth on the coating and phase stability in the coating/substrate interface. The samples were heated up to $700{ }^{\circ} \mathrm{C}$ with slow ramp rate $\left(5^{\circ} \mathrm{C} / \mathrm{min}\right)$ and the temperature was maintained for 20 hours. As shown in Fig. 8b, oxygen permeation through the coating was significantly mitigated and the thin oxide layer of thickness of $750 \mathrm{~nm}$ formed on the top surface of the coating during the 20-hour oxidation. In contrast, the bare Zirc-4 substrate developed about a $65 \mu \mathrm{m}$ thick oxide layer. This suggests that oxidation resistance factor of improvement of the coating is more than 85 compared to bare Zirc- 4 at $700{ }^{\circ} \mathrm{C}$ air. The very near-surface atomic percent of the oxide layer was $14 \%-\mathrm{Zr}, 19 \%-\mathrm{Si}$, and $66 \%-\mathrm{O}$ as measured by XPS (see Table 4) and corresponding binding energy spectra are identical to those of thin $\mathrm{ZrSi}_{2}$ layer $\left(\mathrm{ZrSi}_{2} \# 2\right)$ after the $700{ }^{\circ} \mathrm{C}$ for 5-hours air oxidation. The protective nature for the coating is mainly attributed by the $\mathrm{SiO}_{2}$ and $\mathrm{ZrSiO}_{4}$ oxide layer.

The XRD pattern (Fig. 8c) revealed not only $\mathrm{ZrSi}_{2}$ arising from crystallization of the unreacted coating and zirconium substrate peaks, but also a broad halo in the range of $24^{\circ}$ to $30^{\circ}$ in 20. Possible phases for the broad hump are $\mathrm{ZrSi}_{2}, \mathrm{SiO}_{2}$ (quartz), and $\mathrm{ZrSiO}_{4}$ listed as follows: $\mathrm{ZrSi}_{2}(040)$ at $24.05^{\circ}, \mathrm{ZrSi}_{2}(021)$ at $24.79^{\circ}, \mathrm{ZrSi}_{2}(130)$ at $30.19^{\circ}, \mathrm{SiO}_{2}(011)$ at $25.16^{\circ}, \mathrm{SiO}_{2}$ (220) at $28.41^{\circ}, \mathrm{SiO}_{2}(310)$ at $28.48^{\circ}$, and $\mathrm{ZrSiO}_{4}(200)$ at $26.67^{\circ}$. The XRD pattern would be a superposition of the nanocrystalline phases and amorphous phase, assuming that nanocrystalline 
phases $\left(\mathrm{ZrSiO}_{2}, \mathrm{SiO}_{2}\right.$, and $\left.\mathrm{ZrSi}_{2}\right)$ were precipitating in amorphous oxide matrix in the progress of $700{ }^{\circ} \mathrm{C}$ oxidation. The phase of the thin protective oxide layer is also consistent with an oxide layer formed on bulk $\mathrm{ZrSi}_{2}$ in $700{ }^{\circ} \mathrm{C}$ in ambient air. [8] In addition, the silicon diffusion zone into the Zirc-4 alloy of thickness of $630 \mathrm{~nm}$ was identified. Interestingly, the silicon atoms were supplied from about $1.4 \mu \mathrm{m}$ of the $\mathrm{ZrSi}_{2}$ coating contacting with the substrate because the region displayed silicon reduction $\left(\mathrm{ZrSi}_{2} \rightarrow \mathrm{ZrSi}_{1.5}\right)$ and formation of nano-scale pores due to clustering of vacancies from the substitutional diffusion of Si (dark spots in Fig. 8b).

The high temperature oxidation tests for the optimized coatings were conducted at $1000{ }^{\circ} \mathrm{C}$ for 1 hour and $1200{ }^{\circ} \mathrm{C}$ for 10 minutes. For these tests, the coated samples were inserted directly in a pre-heated furnace resulting in a rapid heating rate. After the exposure, the samples were aircooled to room temperature. These tests demonstrated material degradation due to oxidation and thermal shock. For these tests, two types of samples were evaluated, (i) as-deposited coating and (ii) after pre-oxidation at $700{ }^{\circ} \mathrm{C}$ air for 5 hours. The pre-oxidation condition was the same as was used for the oxidation tests used for thin coatings discussed earlier. Thus the pre-oxidized samples used for the $1000{ }^{\circ} \mathrm{C}$ and $1200{ }^{\circ} \mathrm{C}$ would have the same submicron thickness protective oxide layer. As shown in Fig. 9a and b, significant differences in surface morphology between the as-deposited coating and the pre-oxidized coating were observed after the $1000{ }^{\circ} \mathrm{C}$ oxidation. Micron-scale cracks were observed (Fig. 9a) on the entire area of the as-deposited coating, indicating the coating did not provide the necessary oxidation resistance. The degradation of the as-deposited coating might be explained by the absence of the protective oxide layer and loss of thermal stability of the coating. A sudden temperature surge to $1000{ }^{\circ} \mathrm{C}$ in air produced $\mathrm{ZrO}_{2}$ on the surface due to silicon inward diffusion rather than formation of the $\mathrm{Zr}$-Si-O protective oxide layer. As discussed in the previous section, silicon diffusion from the $\mathrm{ZrSi}_{2}$ coating to $\mathrm{Zirc}-4$ 
substrate was identified at $700{ }^{\circ} \mathrm{C}$ in both oxidation and annealing. Increase of Zr-to-Si ratio on the oxidized surface at $1000{ }^{\circ} \mathrm{C}$ without the pre-oxidation as confirmed in XPS analysis (Table 4), and the local silicon rich area in the cross-sectional image of the coating (Fig. 9c) also support this explanation. According to the diffusion couple experiments between $\mathrm{Ti}_{3} \mathrm{SiC}_{2}$ and Zirc-4 [23], the effective diffusion coefficient of Si in Zirc-4 at $1300{ }^{\circ} \mathrm{C}$ was approximately six times larger than that at $1100{ }^{\circ} \mathrm{C}$. Therefore, remarkably rapid silicon loss of the coating, which accelerated by the surface oxidation at $1000^{\circ} \mathrm{C}$ in the absence of the protective layer, generated microstructural defects (i.e., clusters of voids) in the coating, which induced the crack formation and intensified the material degradation. On the other hand, not only no noticeable defects such as delamination, cracks, or spallation but also higher silicon concentration compared to zirconium on the very near-surface was observed on the pre-oxidized coating surfaces with the $1000{ }^{\circ} \mathrm{C}$ and $1200{ }^{\circ} \mathrm{C}$ exposures.

The protective nature of the top oxide layer formed on the pre-oxidized sample was also confirmed in the cross-sectional SEM image of the sample after the $1000{ }^{\circ} \mathrm{C}$ and $1200{ }^{\circ} \mathrm{C}$ oxidation tests (Fig. 10). After oxidation at $700{ }^{\circ} \mathrm{C}$ for 5 hours followed by the $1000{ }^{\circ} \mathrm{C}$ for 1 hour, total thickness of the oxide scale for the coating was about $7 \mu \mathrm{m}$, but that of the bare Zirc-4 oxidized at the same condition was about $89 \mu \mathrm{m}$. However, the as-deposited coating (i.e., without pre-oxidation) after the test had thicker oxide scale (approximately $106 \mu \mathrm{m}$ ) than the bare Zirc-4, resulting from oxygen ingress through the cracks as observed in Fig. 9a and 9c. The oxygen penetration depth for the pre-oxidized coating after the $1000{ }^{\circ} \mathrm{C}$ test was also measured by EDS line scan analysis as shown in Fig. 10b. The pre-conditioning produced about $730 \mathrm{~nm}$ thickness oxide layer on the top, $\mathrm{ZrO}_{2}(\sim 6.3 \mu \mathrm{m}), \mathrm{ZrSi}_{2}(\sim 0.9 \mu \mathrm{m})$, and $\mathrm{ZrSi}$ layer $(\sim 3.5 \mu \mathrm{m})$ subsequently. In addition, the oxide layer thickness of the pre-oxidized coating after the $1200{ }^{\circ} \mathrm{C}$ 
test was about $20 \mu \mathrm{m}$, which was nearly one tenth of oxide scale of the bare Zirc-4 (about 208 $\mu \mathrm{m})$ at the condition. The oxide scale for the coated samples consisted of thin protective layer (750 nm) on the top, thick $\mathrm{ZrO}_{2}$ layer $(\sim 17 \mu \mathrm{m}), \mathrm{ZrSi}_{2}$ islands, and $\mathrm{ZrSi}$ layer $(\sim 2.3 \mu \mathrm{m})$.

Interestingly, the protective oxide layer formed on the pre-oxidation $\left(700{ }^{\circ} \mathrm{C}\right)$ transformed to nanoscale $\mathrm{ZrO}_{2}$ phase particulates and $\mathrm{SiO}_{2}$ matrix at the $1000{ }^{\circ} \mathrm{C}$ and $1200{ }^{\circ} \mathrm{C}$ exposures as shown in Fig. 10c and 10d. The microstructure was not identified in the oxide scale at $700{ }^{\circ} \mathrm{C}$ (Fig. 5f and Fig. 8b).

The phase transformation from the $\mathrm{Zr}$-Si-O oxide mixture to the $\mathrm{ZrO}_{2}$ and $\mathrm{SiO}_{2}$ phase was also reported in annealing of mixture of $\mathrm{ZrO}_{2}$ and $\mathrm{SiO}_{2}$ thin film at $900{ }^{\circ} \mathrm{C}$ for 60 seconds [24] and oxidation of bulk $\mathrm{ZrSi}_{2}$ at $1000{ }^{\circ} \mathrm{C}$ and $1200{ }^{\circ} \mathrm{C}$ for 5 hours in ambient air. [8] The authors suggested that a thermodynamic driving force exists in disordered $\mathrm{Zr}-\mathrm{Si}$-O mixture, leading to nucleation and growth of $\mathrm{ZrO}_{2}$ in $\mathrm{SiO}_{2}$ matrix instead of formation of $\mathrm{ZrSiO}_{4}$. During the preconditioning, the oxide layer consisting of a mixture of the nanocrystalline phases and amorphous phase generates, which might heal inherent microstructural defects (i.e., conical defects) so that the oxide layer hindered oxygen permeation during the $1000{ }^{\circ} \mathrm{C}$ and $1200{ }^{\circ} \mathrm{C}$ oxidation. In addition, the multi-layered scale structure at the high temperatures evolves due to slow oxidation kinetics arising from the thin protective layer. The partial pressure for oxygen might be significantly decreased in the protective layer, resulting in a slower oxidation process of the rest of the $\mathrm{ZrSi}_{2}$ coating. In the meantime, the silicon in the coating migrated inward to the substrate, increasing activity of zirconium. The mobile silicon atoms reacted with the substrate and formed the $\mathrm{ZrSi}_{2}$ and $\mathrm{ZrSi}$ layers, which is supported by the zirconium-silicon diffusion couple experiments at $900{ }^{\circ} \mathrm{C}$ to $1400{ }^{\circ} \mathrm{C}$ in inert environments. Bertolino et al. [25] reported formation of the $\mathrm{ZrSi}_{2}$ and $\mathrm{ZrSi}$ layers in the conditions. When oxygen diffused through the 
protective layer and reacted with zirconium atoms, the $\mathrm{ZrO}_{2}$ scale was formed. Lastly, it is expected that oxidation of the $\mathrm{ZrSi}_{2}$ coating with the pre-oxidation at even higher temperatures (e.g., $1300{ }^{\circ} \mathrm{C}$ or $1400{ }^{\circ} \mathrm{C}$ ) produces micron-grained $\mathrm{ZrSiO}_{4}$ phase in the protective layer by solid state reaction of the $\mathrm{ZrO}_{2}$ particulates and the $\mathrm{SiO}_{2}$ matrix, which would provide enhanced oxidation resistance. [26]

\section{Conclusions}

Optimization of zirconium-silicide coating on Zircaloy-4 substrate prepared by a magnetron sputter deposition was investigated to improve oxidation resistance in a high temperature air environment. Three coating stoichiometries, namely, $\mathrm{Zr}_{2} \mathrm{Si}, \mathrm{ZrSi}$, and $\mathrm{ZrSi}_{2}$ were deposited at room temperature showed columnar structures. Coating composition and argon pressure during deposition were adjusted to attain minimal weight gain and oxygen penetration at $700{ }^{\circ} \mathrm{C}$ air. Initial air-oxidation tests at $700{ }^{\circ} \mathrm{C}$ air for five hours showed the $\mathrm{ZrSi}_{2}$ coating deposited at 0.53 Pa to have the best oxidation resistance due to a denser microstructure and formation of a protective oxide layer. It is speculated that the oxidation resistance of the protective layer is attributed to the nanocrystalline $\mathrm{SiO}_{2}$ and $\mathrm{ZrSiO}_{4}$ phases in the amorphous matrix. SEM-EDS examination indicated ready mobility of Si outward to form an oxide and inward to form and intermetallic compound with the Zircoaloy-4 substrate. Thicker $\mathrm{ZrSi}_{2}$ coating $(3.9 \mu \mathrm{m})$ was synthesized using these optimized parameters. The thicker coatings showed improvement of almost two orders of magnitude when compared to bare Zircaloy-4 after air-oxidation at $700{ }^{\circ} \mathrm{C}$ for 20-hours. Pre-oxidation of $\mathrm{ZrSi}_{2}$ coating at $700{ }^{\circ} \mathrm{C}$ for 5 hours significantly mitigated oxygen diffusion in air-oxidation tests at $1000{ }^{\circ} \mathrm{C}$ for 1-hour and $1200{ }^{\circ} \mathrm{C}$ for 10 -minutes; the total oxide layer thickness for $1000{ }^{\circ} \mathrm{C}$ and $1200{ }^{\circ} \mathrm{C}$ tests to be only $7 \mu \mathrm{m}$ and $20 \mu \mathrm{m}$, respectively. On the other hand, the bare Zircaloy-4 showed $89 \mu \mathrm{m}$ and $208 \mu \mathrm{m}$ oxide scale thickness, respectively, 
under these oxidation test conditions. No spallation or cracks were observed in the $\mathrm{ZrSi}_{2}$ coating due to air cooling to room temperature after high temperature oxidation tests. The results of this initial study suggest that the $\mathrm{ZrSi}_{2}$ coating could be a good candidate coating for protection $\mathrm{Zr}$ alloy (or other substrates) under air oxidation conditions.

\section{Acknowledgments}

The authors are grateful to Elliot Strand for sample preparation to SEM imaging and Dr. Li He for technical supports of TEM imaging. This work is sponsored by the U.S. Department of Energy, Office of Nuclear Energy, Nuclear Engineering University Programs (NEUP), under grant number DE-NE0008300. 


\section{References}

[1] M. Steinbrïck, Prototypical experiments relating to air oxidation of Zircaloy-4 at high temperatures, J. Nucl. Mater. 392 (2009) 531-544. doi:10.1016/j.jnucmat.2009.04.018.

[2] M. Steinbrück, M. Böttcher, Air oxidation of Zircaloy-4, M5® and ZIRLO ${ }^{\text {TM }}$ cladding alloys at high temperatures, J. Nucl. Mater. 414 (2011) 276-285.

doi:10.1016/j.jnucmat.2011.04.012.

[3] B.A. Pint, K.A. Terrani, Y. Yamamoto, L.L. Snead, Material Selection for Accident Tolerant Fuel Cladding, Metall. Mater. Trans. E. 2 (2014) 190-196. doi:10.1007/s40553015-0056-7.

[4] S. Becker, A. Rahmel, M. Schutze, Oxidation of $\mathrm{TiSi}_{2}$ and $\mathrm{MoSi}_{2}$, Solid State Ionics. 5356 (1992) 280-289. doi:10.1016/0167-2738(92)90391-2.

[5] D.A. Berztiss, R.R. Cerchiara, E.A. Gulbransen, F.S. Pettit, G.H. Meier, Oxidation of $\mathrm{MoSi}_{2}$ and comparison with other silicide materials, Mater. Sci. Eng. A. 155 (1992) 165181. doi:10.1016/0921-5093(92)90324-T.

[6] W.J. Strydom, J.C. Lombaard, R. Pretorius, Thermal oxidation of the silicides $\mathrm{CoSi}_{2}$, $\mathrm{CrSi}_{2}, \mathrm{NiSi}_{2}, \mathrm{PtSi}, \mathrm{TiSi}_{2}$ and $\mathrm{ZrSi}_{2}$, Thin Solid Films. 131 (1985) 215-231. doi:10.1016/0040-6090(85)90142-7.

[7] M. Wang, B.O. Sundman, Thermodynamic Assessment of the Si-Zr System, Capphad. 18 (2000) 319-327. doi:http://dx.doi.org/10.1111/j.1551-2916.2004.00683.x.

[8] H. Yeom, B. Maier, Evolution of Multi-Layered Scale Structures during High Temperature Oxidation of $\mathrm{ZrSi}_{2}$, J. Mater. Res. 31 (2016) 3409-3419.

[9] H. Geßwein, A. Pfrengle, J.R. Binder, J. Haußelt, Kinetic model of the oxidation of $\mathrm{ZrSi}_{2}$ powders, J. Therm. Anal. Calorim. 91 (2007) 517-523. doi:10.1007/s10973-007-8461-5.

[10] S. Knittel, S. Mathieu, M. Vilasi, The oxidation behaviour of uniaxial hot pressed $\mathrm{MoSi}_{2}$ in air from 400 to 1400 degrees C, Intermetallics. 19 (2011) 1207-1215. doi:10.1016/j.intermet.2011.03.029.

[11] P. Zeman, J. Musil, Difference in high-temperature oxidation resistance of amorphous ZrSi-N and W-Si-N films with a high Si content, Appl. Surf. Sci. 252 (2006) 8319-8325. doi:10.1016/j.apsusc.2005.11.038.

[12] C.K. Chung, T.S. Chen, N.W. Chang, S.C. Chang, M.W. Liao, Oxidation resistance and mechanical property of cosputtered quasi-amorphous Ta-Si-N films under vacuum rapid thermal annealing, Surf. Coatings Technol. 205 (2010) 1268-1272.

doi:10.1016/j.surfcoat.2010.08.080.

[13] J.A. Thornton, The microstructure of sputter-deposited coatings, J. Vac. Sci. Technol. A Vacuum, Surfaces, Film. 4 (1986) 3059. doi:10.1116/1.573628.

[14] J.A. Thornton, High Rate Thick Film Growth, Annu. Rev. Mater. Res. 7 (1977) 239-260.

[15] A.P. Dementjev, O.P. Ivanova, L.A. Vasilyev, A. V. Naumkin, D.M. Nemirovsky, D.Y. Shalaev, Altered layer as sensitive initial chemical state indicator*, J. Vac. Sci. Technol. 
A Vacuum, Surfaces, Film. 12 (1994) 423-427. doi:10.1116/1.579258.

[16] R.B. Shalvoy, P.J. Reucroft, Characterization of coprecipitated nickel on silica methanation catalysts by X-ray photoelectron spectroscopy, J. Catal. 56 (1979) 336-348. doi:10.1016/0021-9517(79)90126-X.

[17] T. Romotowski, J. Komorek, J. Stoch, V.M. Mastikhin, ZSM-5 zeolite modified with zirconyl ions, Pol. J. Chem. 69 (1995) 621-626.

[18] W.C. Butterman, Zircon Stability and $\mathrm{ZrO}_{2}-\mathrm{SiO}_{2}$ Phase Diagram, Am. Mineral. 52 (1967) 880 .

[19] B.W. Busch, W.H. Schulte, E. Garfunkel, T. Gustafsson, Oxygen exchange and transport in thin zirconia films on Si (100), Phys. Rev. B. 62 (2000) 290-293.

[20] N.S. Jacobson, Corrosion of Silicon-Based Ceramics in Combustion Environments, J. Am. Ceram. Soc. 76 (1993) 3-28. doi:10.1111/j.1151-2916.1993.tb03684.x.

[21] P. Chraska, K. Neufuss, H. Herman, Plasma spraying of zircon, J. Therm. Spray Technol. 6 (1997) 445-448. doi:10.1007/s11666-997-0029-1.

[22] K.N. Lee, Current status of environmental barrier coatings for Si-based ceramics, Surf. Coatings Technol. 133-134 (2000) 1-7. doi:10.1016/S0257-8972(00)00889-6.

[23] D.J. Tallman, J. Yang, L. Pan, B. Anasori, M.W. Barsoum, Reactivity of Zircaloy-4 with $\mathrm{Ti}_{3} \mathrm{SiC}_{2}$ and $\mathrm{Ti}_{2} \mathrm{AlC}$ in the $1100-1300^{\circ} \mathrm{C}$ temperature range, J. Nucl. Mater. 460 (2015) 122-129. doi:10.1016/j.jnucmat.2015.02.006.

[24] G. Lucovsky, G.B. Rayner, Microscopic model for enhanced dielectric constants in low concentration $\mathrm{SiO}_{2}$-rich noncrystalline $\mathrm{Zr}$ and Hf silicate alloys, Appl. Phys. Lett. 77 (2000) 2912. doi:10.1063/1.1320860.

[25] N. Bertolino, U. Anselmi-Tamburini, F. Maglia, G. Spinolo, Z.A. Munir, Combustion synthesis of Zr-Si intermetallic compounds, J. Alloys Compd. 288 (1999) 238-248. doi:10.1016/S0925-8388(99)00077-8.

[26] C. Veytizou, J.F. Quinson, O. Valfort, G. Thomas, Zircon formation from amorphous silica and tetragonal zirconia: Kinetic study and modelling, Solid State Ionics. 139 (2001) 315-323. doi:10.1016/S0167-2738(01)00676-2. 


\section{Tables}

Table 1. Summary of zirconium silicide coatings deposited and investigated in this study.

\begin{tabular}{|c|c|c|c|c|c|}
\hline Sample ID & Target composition & Ar pressure $(\mathrm{Pa})$ & Deposition rate $(\mathrm{nm} / \mathrm{min})$ & \# of steps & Experimental Conditions \\
\hline $\mathrm{Zr}_{2} \mathrm{Si} \# 1$ & $\mathrm{Zr}_{2} \mathrm{Si}$ & 1.33 & 6.12 & 1 & $700^{\circ} \mathrm{C}$ air for 5 hours \\
\hline $\mathrm{ZrSi} \# 1$ & $\mathrm{ZrSi}$ & 1.33 & 5.81 & 1 & $700^{\circ} \mathrm{C}$ air for 5 hours \\
\hline $\mathrm{ZrSi}_{2} \# 1$ & $\mathrm{ZrSi}_{2}$ & 1.33 & 5.39 & 1 & $700{ }^{\circ} \mathrm{C}$ air for 5 hours \\
\hline $\mathrm{Zr}_{2} \mathrm{Si} \# 2$ & $\mathrm{Zr}_{2} \mathrm{Si}$ & 0.53 & 5.30 & 1 & $\begin{array}{l}700^{\circ} \mathrm{C} \text { air for } 5 \text { hours } \\
700^{\circ} \mathrm{C} \mathrm{Ar} \text { for } 5 \text { hours }\end{array}$ \\
\hline $\mathrm{ZrSi} \# 2$ & $\mathrm{ZrSi}$ & 0.53 & 4.97 & 1 & $\begin{array}{l}700{ }^{\circ} \mathrm{C} \text { air for } 5 \text { hours } \\
700{ }^{\circ} \mathrm{C} \text { Ar for } 5 \text { hours }\end{array}$ \\
\hline $\mathrm{ZrSi}_{2} \# 2$ & $\mathrm{ZrSi}_{2}$ & 0.53 & 4.80 & 1 & $\begin{array}{c}700^{\circ} \mathrm{C} \text { air for } 5 \text { hours } \\
700^{\circ} \mathrm{C} \text { Ar for } 5 \text { hours } \\
700{ }^{\circ} \mathrm{C} \text { air for } 20 \text { hours }\end{array}$ \\
\hline $\mathrm{ZrSi}_{2} \# 3$ & $\mathrm{ZrSi}_{2}$ & 0.53 & 4.80 & 6 & $\begin{array}{c}1000{ }^{\circ} \mathrm{C} \text { air for } 1 \text { hour } \\
1200{ }^{\circ} \mathrm{C} \text { air for } 10 \text { minutes }\end{array}$ \\
\hline
\end{tabular}


Table 2. Composition, phase content, microstructure, and coating thickness of the as-deposited thin coatings.

\begin{tabular}{|cccccc|}
\hline Sample ID & Ar pressure $(\mathrm{Pa})$ & $\begin{array}{c}\text { Coating } \\
\text { composition }\end{array}$ & $\begin{array}{c}\text { Major structural } \\
\text { phase }\end{array}$ & Microstructure & Thickness (nm) \\
\hline $\mathrm{Zr}_{2} \mathrm{Si \# 1}$ & 1.33 & $\mathrm{Zr}_{2.2} \mathrm{Si}_{1.0}$ & Amorphous & Long, tapered, columnar & 920 \\
$\mathrm{ZrSi} 1$ & 1.33 & $\mathrm{Zr}_{1.1} \mathrm{Si}_{1.0}$ & Amorphous & Long, tapered, columnar & 870 \\
$\mathrm{ZrSi}{ }_{2} \# 1$ & 1.33 & $\mathrm{Zr}_{1.0} \mathrm{Si}_{1.9}$ & Amorphous & Long, tapered, columnar & 800 \\
$\mathrm{Zr}_{2} \mathrm{Si} \# 2$ & 0.53 & $\mathrm{Zr}_{2.2} \mathrm{Si}_{1.0}$ & Amorphous & Short, dense, columnar & 800 \\
$\mathrm{ZrSi}$ 2 & 0.53 & $\mathrm{Zr}_{1.0} \mathrm{Si}_{1.0}$ & Amorphous & Short, dense, columnar & 750 \\
$\mathrm{ZrSi}{ }_{2} \# 2$ & 0.53 & $\mathrm{Zr}_{1.0} \mathrm{Si}_{2.2}$ & Amorphous & Short, dense, columnar & 720 \\
\hline
\end{tabular}


Table 3. XPS compositional analysis of the coatings after $700{ }^{\circ} \mathrm{C}$ for 5 -hours air oxidation.

Numbers are in atomic percent for each element on the surface. The last column indicates the atomic percent ratio of zirconium and silicon.

\begin{tabular}{|cccccc|}
\hline Sample ID & Si2p & $\mathrm{Zr3d}$ & $\mathrm{O} 1 \mathrm{~s}$ & $\mathrm{C} 1 \mathrm{~s}$ & $\mathrm{Zr}: \mathrm{Si}$ \\
\hline $\mathrm{Zr}_{2} \mathrm{Si} \# 2$ & 8.05 & 22.25 & 64.59 & 5.11 & $2.8: 1.0$ \\
$\mathrm{ZrSi} \# 2$ & 12.30 & 18.88 & 65.65 & 3.17 & $1.5: 1.0$ \\
$\mathrm{ZrSi}_{2} \# 2$ & 17.92 & 13.09 & 63.64 & 5.34 & $1.0: 1.4$ \\
\hline
\end{tabular}


Table 4. XPS compositional analysis of the optimized coatings $\left(\mathrm{ZrSi}_{2} \# 3\right)$ after the oxidation tests. The numbers are in atomic percent of each element on the very near-surface. The last column shows the atomic percent ratio of zirconium and silicon.

\begin{tabular}{|cccccc|}
\hline Oxidation Test & Si2p & Zr3d & O1s & C1s & Zr : Si \\
\hline $700{ }^{\circ} \mathrm{C}$ for 20 hours & 18.82 & 13.63 & 65.50 & 2.06 & $1.0: 1.4$ \\
$1000{ }^{\circ} \mathrm{C}$ for 1 hour & 15.06 & 17.88 & 64.78 & 1.67 & $1.2: 1.0$ \\
$700{ }^{\circ} \mathrm{C}$ for 5 hours $\rightarrow 1000{ }^{\circ} \mathrm{C}$ for 1 hour & 17.24 & 14.40 & 67.07 & 1.30 & $1.0: 1.2$ \\
$700{ }^{\circ} \mathrm{C}$ for 5 hours $\rightarrow 1200{ }^{\circ} \mathrm{C}$ for 10 minutes & 15.99 & 15.10 & 67.68 & 1.23 & $1.0: 1.1$ \\
\hline
\end{tabular}




\section{List of Figure Captions}

Fig. 1. XRD patterns of thin coatings $\left(\mathrm{Zr}_{2} \mathrm{Si} \# 1, \mathrm{ZrSi} \# 1\right.$, and $\left.\mathrm{ZrSi}_{2} \# 1\right)$ with $2^{\circ}$ incident $\mathrm{X}$-ray beam. Only zirconium peaks from the underlying substrate were identified.

Fig. 2. SEM plan-view images of coatings of (a) $\mathrm{ZrSi}_{2} \# 1$ deposited at $1.33 \mathrm{~Pa}$ Ar gas pressure and (b) $\mathrm{ZrSi}_{2} \# 2$ deposited at $0.53 \mathrm{~Pa}$ Ar gas pressure on Zirc-4 substrate. SEM cross-sectional fracture surface images of (c) $\mathrm{ZrSi}_{2} \# 1$ deposited at $1.33 \mathrm{~Pa}$ Ar gas pressure and (d) $\mathrm{ZrSi}_{2} \# 2$ deposited at $0.53 \mathrm{~Pa}$ Ar gas pressure on a silicon wafer. The dimensional difference for the microstructure in Fig. 2a and Fig. 2c is attributed to nature and roughness of the substrates. The image in Figure 2a was from the coating deposited on 600 grit surface finish Zirc-4 substrate while Fig. $2 \mathrm{c}$ is the image of the coating deposited on atomically smooth Si wafers.

Fig. 3. (a) Cross-sectional bright field TEM image and (b) diffraction pattern of $\mathrm{ZrSi}_{2} \# 2$. The coating of thickness was $3 \mu \mathrm{m}$ and was prepared by a four-step deposition for the diffraction pattern observation because an electron beam should illuminate the area of interested through the SAD aperture $(1 \mu \mathrm{m}$ diameter). Coating growth direction is indicated by the black dot arrow.

Fig. 4. Weight gain of the zirconium-silicide coatings with different compositions $\left(\mathrm{Zr}_{2} \mathrm{Si} \# 2\right.$, $\mathrm{ZrSi} \# 2$, and $\mathrm{ZrSi}_{2} \# 2$ ) in $700{ }^{\circ} \mathrm{C}$ air oxidation test. The coatings were deposited at $0.53 \mathrm{~Pa}$ argon pressure.

Fig. 5. SEM cross sectional images of (a, d) $\mathrm{Zr}_{2} \mathrm{Si} \# 2$, (b, e) $\mathrm{ZrSi} \# 2$, and (c, f) $\mathrm{ZrSi}_{2} \# 2$ coatings at low and high magnifications after $700{ }^{\circ} \mathrm{C}$ for 5 -hours air oxidation test. The high magnification images were acquired in the areas indicated by the red frames in the low magnification images. $\mathrm{Cu}$ layer deposited on the coating surface by electroplating to minimize coating damage and edge retention during the sample preparation. 
Fig. 6. XPS O1s spectra of zirconium-silicide coatings after $700{ }^{\circ} \mathrm{C}$ for 5 -hours oxidation: (a) $\mathrm{Zr}_{2} \mathrm{Si} \# 2$, (b) $\mathrm{ZrSi} \# 2$, and (c) $\mathrm{ZrSi}_{2} \# 2$. The $\mathrm{O} 1 \mathrm{~s}$ spectra were resolved into possible oxide components (red curve: $\mathrm{ZrSiO}_{4}$, green curve: $\mathrm{SiO}_{2}$, and blue curve: $\mathrm{ZrO}_{2}$ ). The measured spectrum is indicated by dark curve.

Fig. 7. SEM cross-sectional images of annealed (a) $\mathrm{Zr}_{2} \mathrm{Si} \# 2$, (b, c) $\mathrm{ZrSi} \# 2$, and $\mathrm{ZrSi}_{2} \# 2$ at $700{ }^{\circ} \mathrm{C}$ for 5 hours in argon gas. Interface between the coating and the substrate and silicon diffused zone are indicated by the red dot line and red arrow, respectively. A ratio of zirconium-to-silicon at the dark cross is stated on each figure, measured by EDS point scan analysis.

Fig. 8. SEM cross-sectional images of (a) as-deposited $\mathrm{ZrSi}_{2}$ coating $\left(\mathrm{ZrSi}_{2} \# 3\right)$ on silicon wafer and (b) oxidized $\mathrm{ZrSi}_{2}$ coating on Zirc-4 at $700{ }^{\circ} \mathrm{C}$ for 20 hours. Interface between the coating and the substrate is indicated by the red dots. (c) XRD pattern for the oxidized $\mathrm{ZrSi}_{2}$ on Zirc-4 at $700{ }^{\circ} \mathrm{C}$ for 20 hours. The dark arrow in Fig. 8c points to broad halo associating with the thin oxide layer in Fig. 8b.

Fig. 9. SEM plan-view images of (a) $\mathrm{ZrSi}_{2} \# 3$ oxidized at $1000{ }^{\circ} \mathrm{C}$ for 1 hour, (b) $\mathrm{ZrSi} i_{2} \# 3$ with pre-oxidation $\left(700{ }^{\circ} \mathrm{C}\right.$ for 5 hours) oxidized at $1000{ }^{\circ} \mathrm{C}$ for 1 hour, and (c) Cross-sectional image of $\mathrm{ZrSi}_{2} \# 3$ oxidized at $1000{ }^{\circ} \mathrm{C}$ for 1 hour, showing cracks and Si rich area in the thick oxide scale. The samples were rapidly heated up to the high temperature air. After the exposure, the coating was air-cooled to room temperature.

Fig. 10. SEM cross-sectional images and EDS line scan of $\mathrm{ZrSi}_{2} \# 3$ with the pre-oxidation after the $1000{ }^{\circ} \mathrm{C}$ for 1-hour air oxidation: (a) Low magnification and (b) EDS line scan result corresponding to Fig 9a. The red dots and the red solid arrow in Fig. 9a refers to interface between the coating and substrate and the EDS scan direction, respectively. High magnification 
cross-sectional SEM images of top surface of the pre-oxidized coatings after (c) the $1000{ }^{\circ} \mathrm{C}$ for 1 hour and (d) the $1200{ }^{\circ} \mathrm{C}$ for 10 minutes. The red solid arrows in Fig. 9c and Fig. 9d refer to the thin protective layer consisting of nanoscale $\mathrm{ZrO}_{2}$ phases in $\mathrm{SiO}_{2}$ matrix. 


\section{Figures}

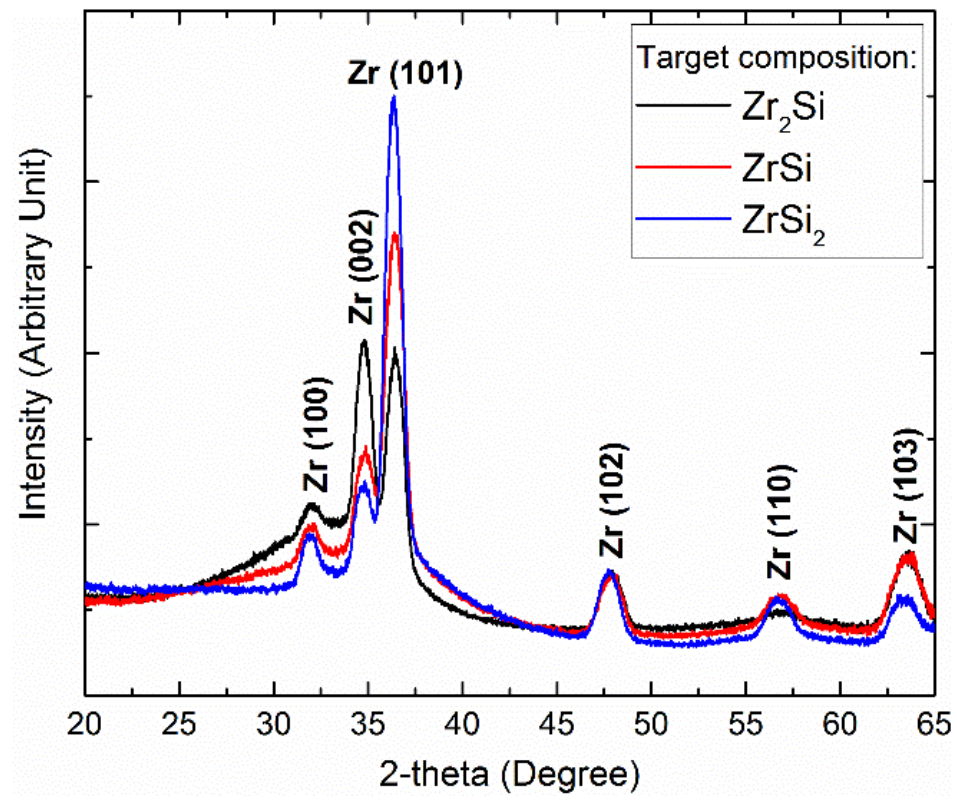

FIG 1

(a)

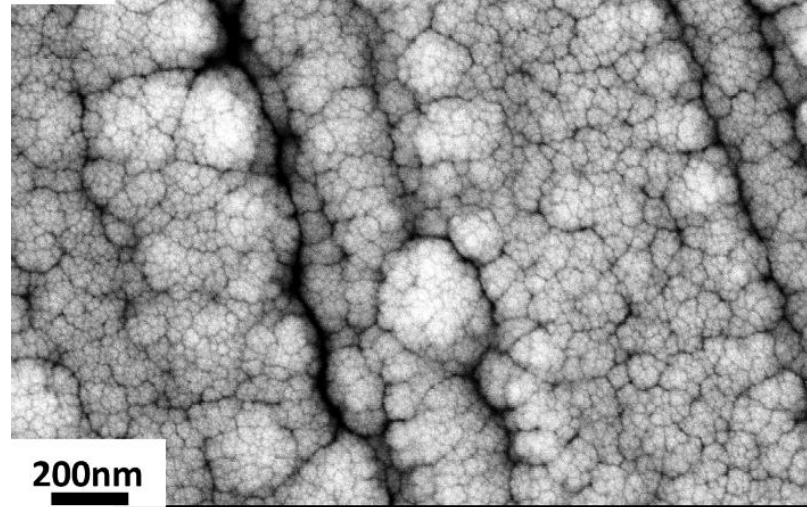

(c)

(b)

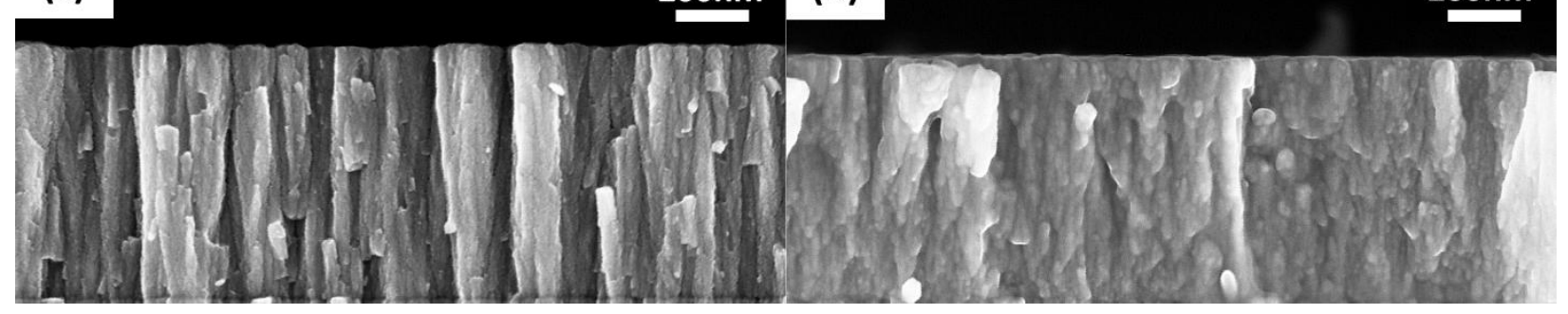

FIG 2 


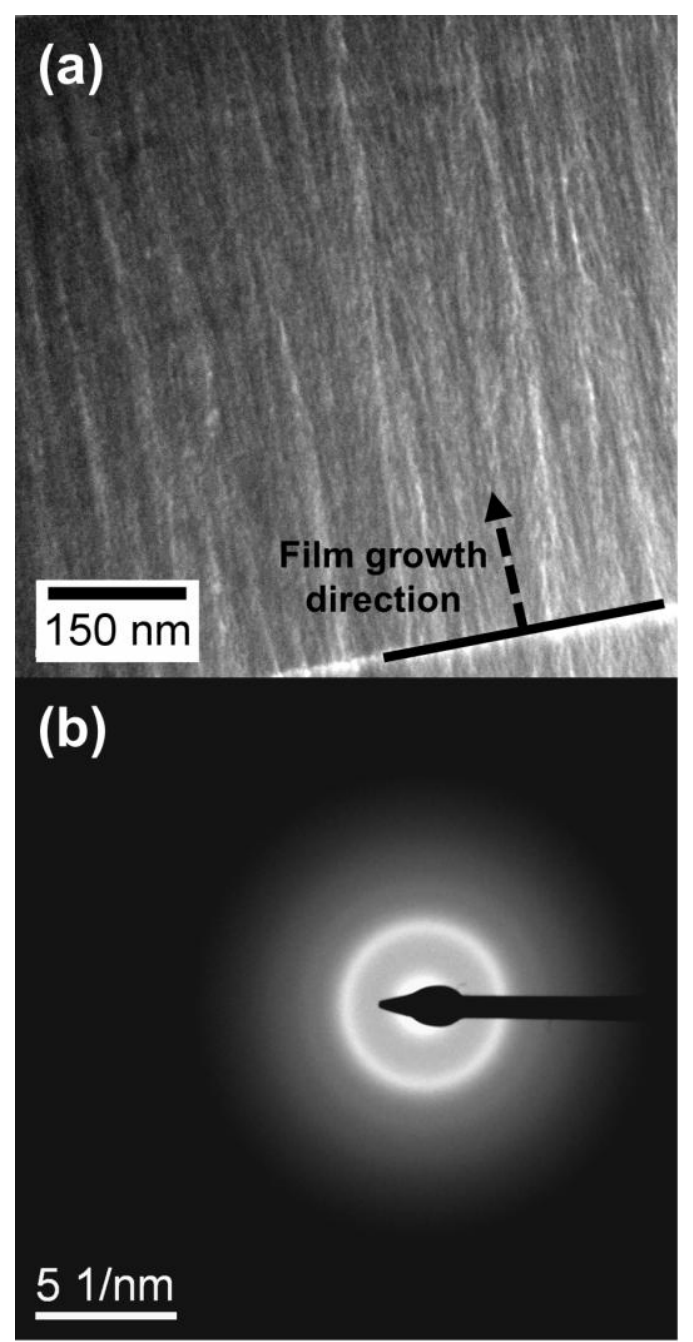

FIG 3

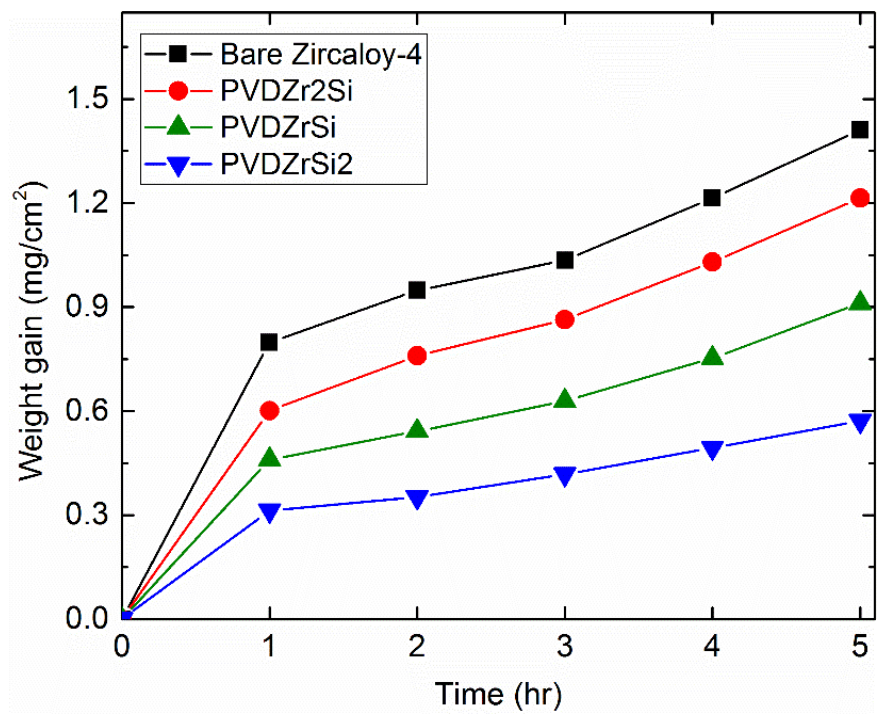

FIG 4 


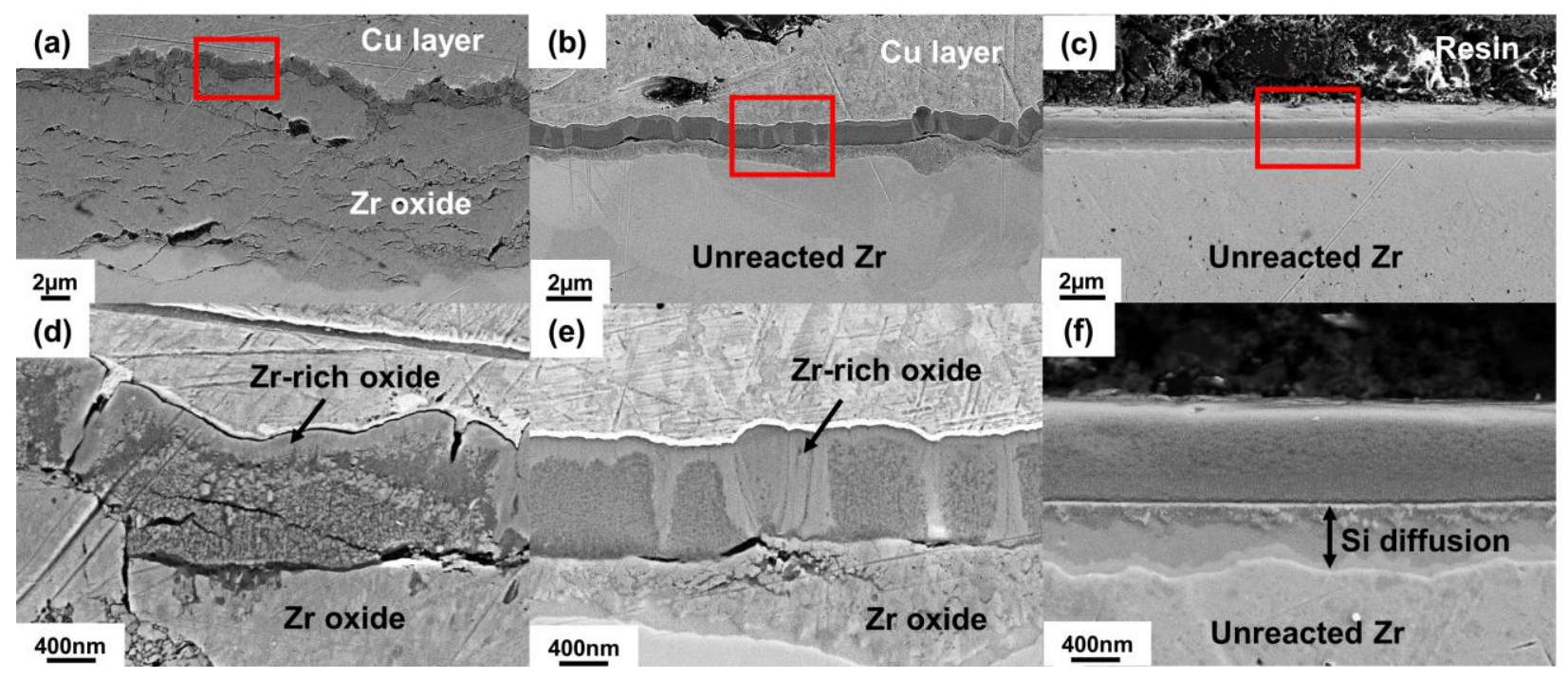

FIG 5 

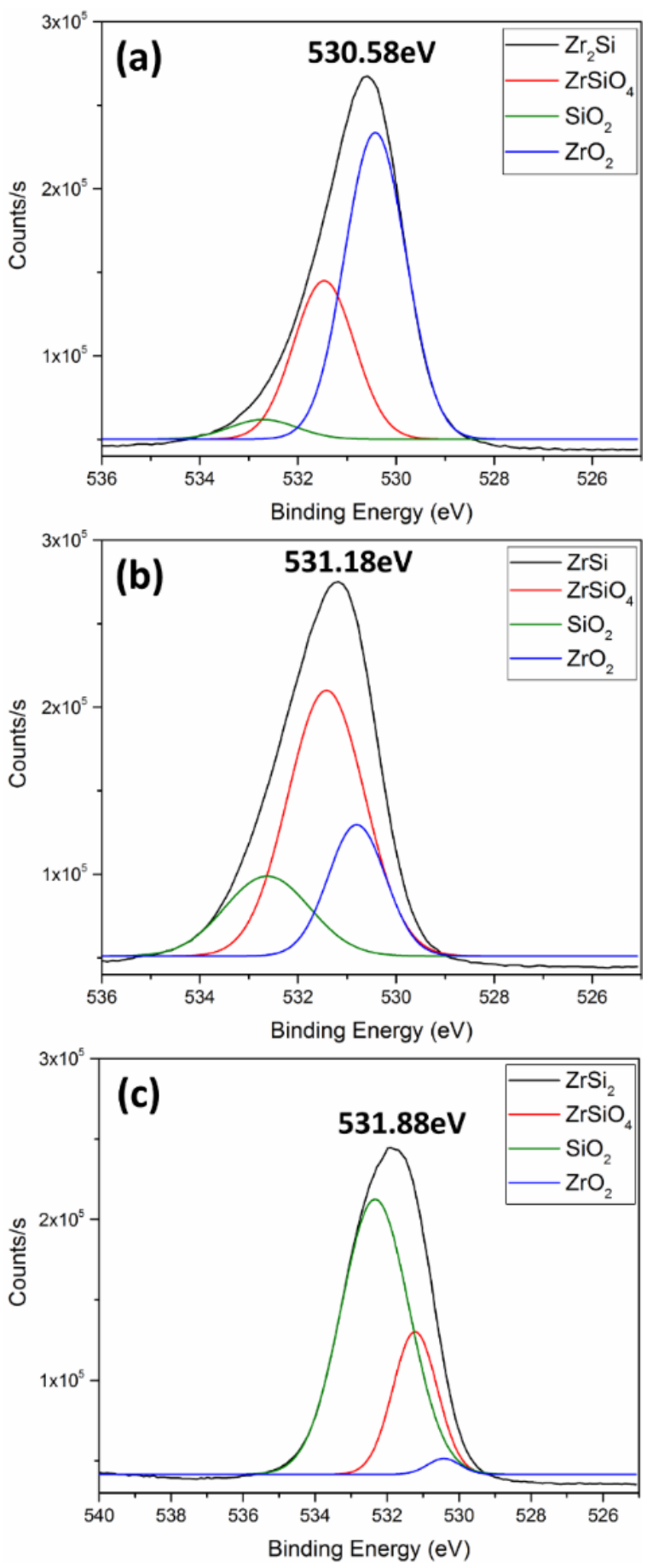

FIG 6 


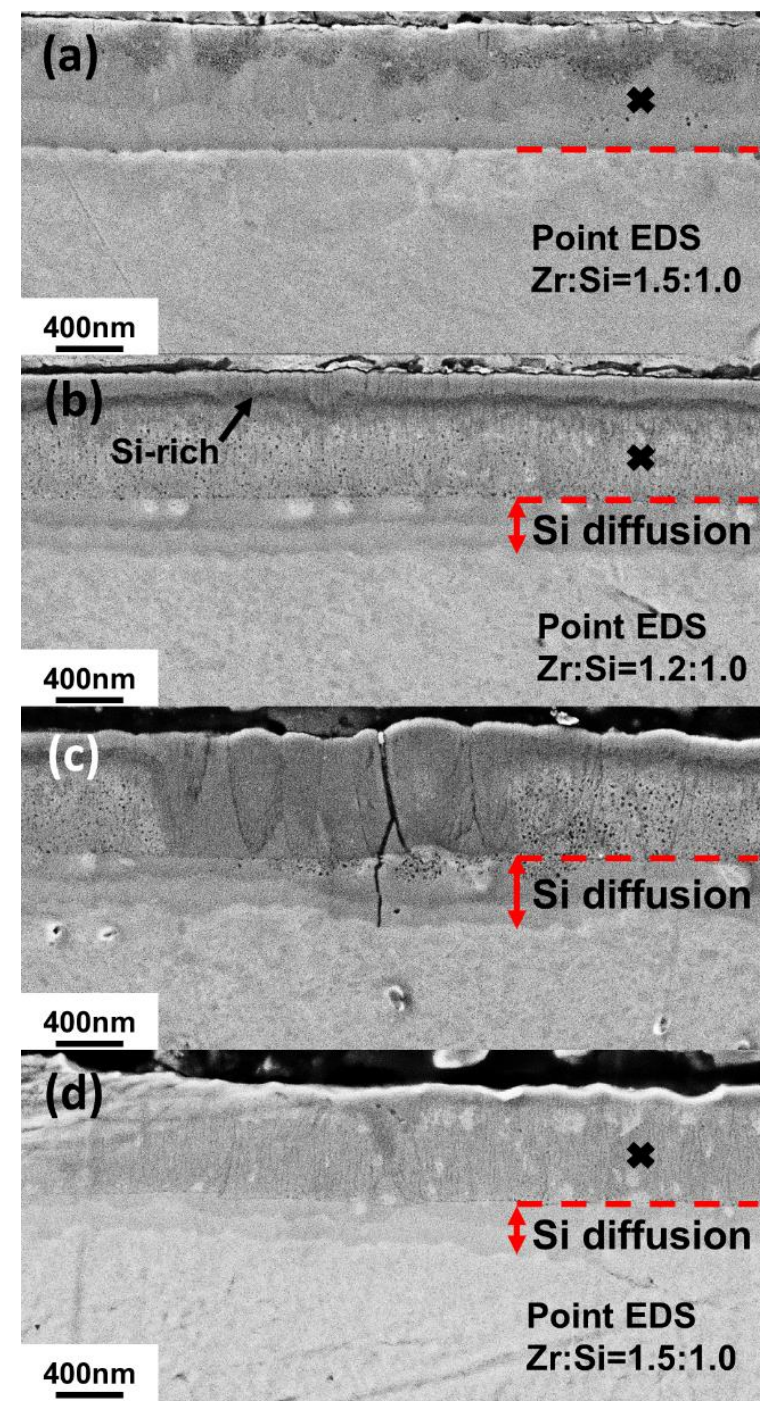

FIG 7 


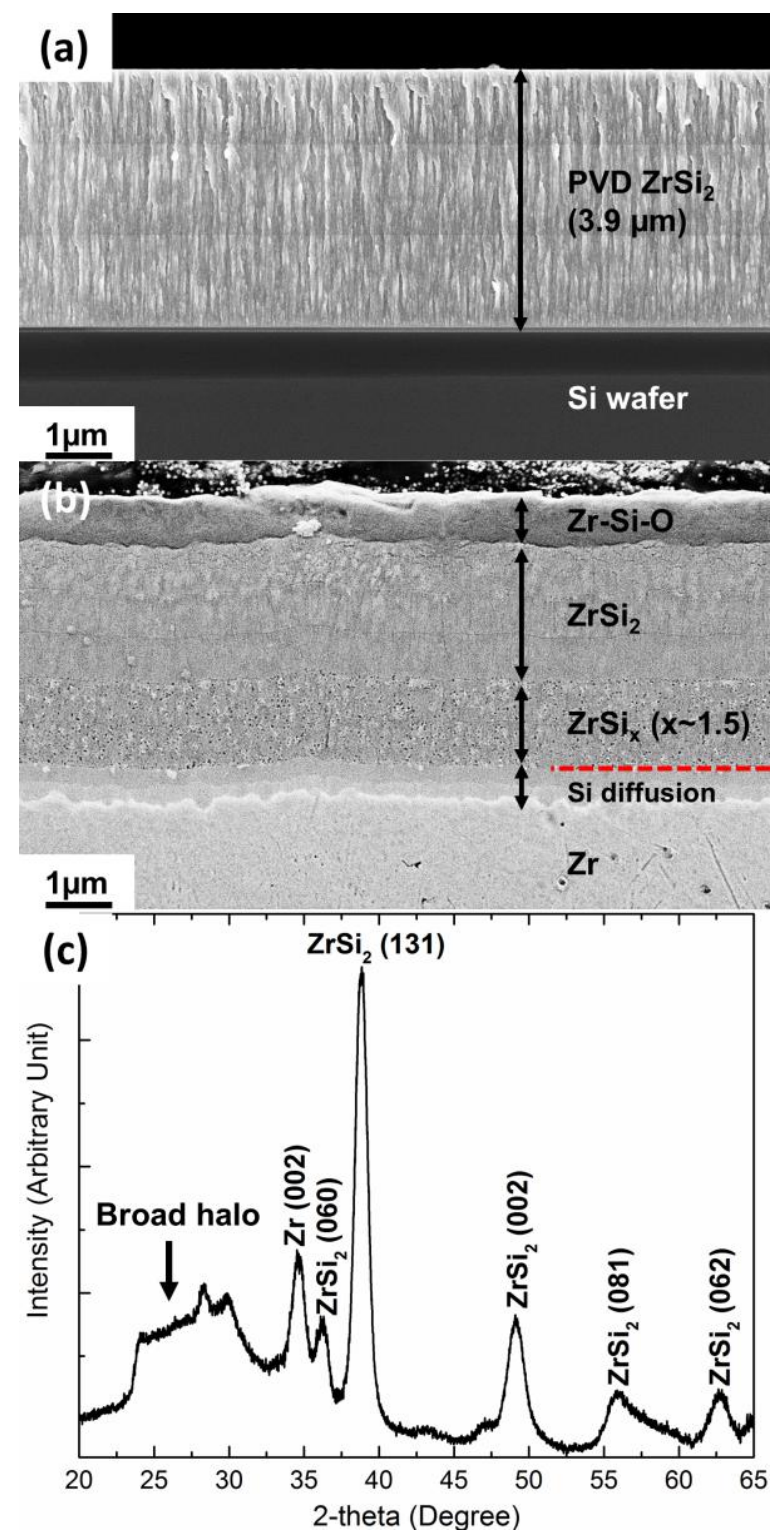

FIG 8
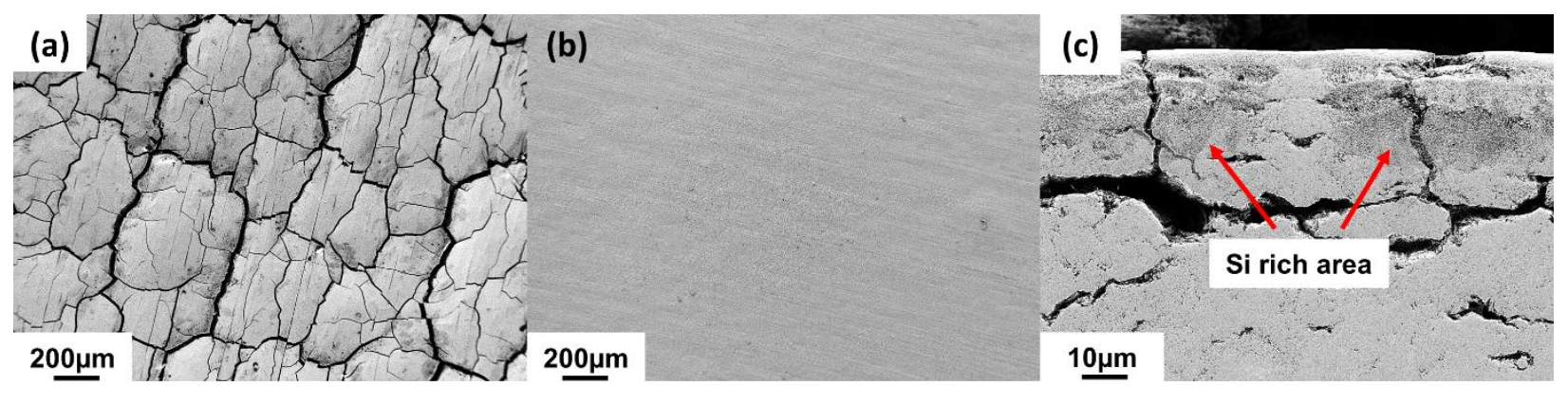

FIG 9 

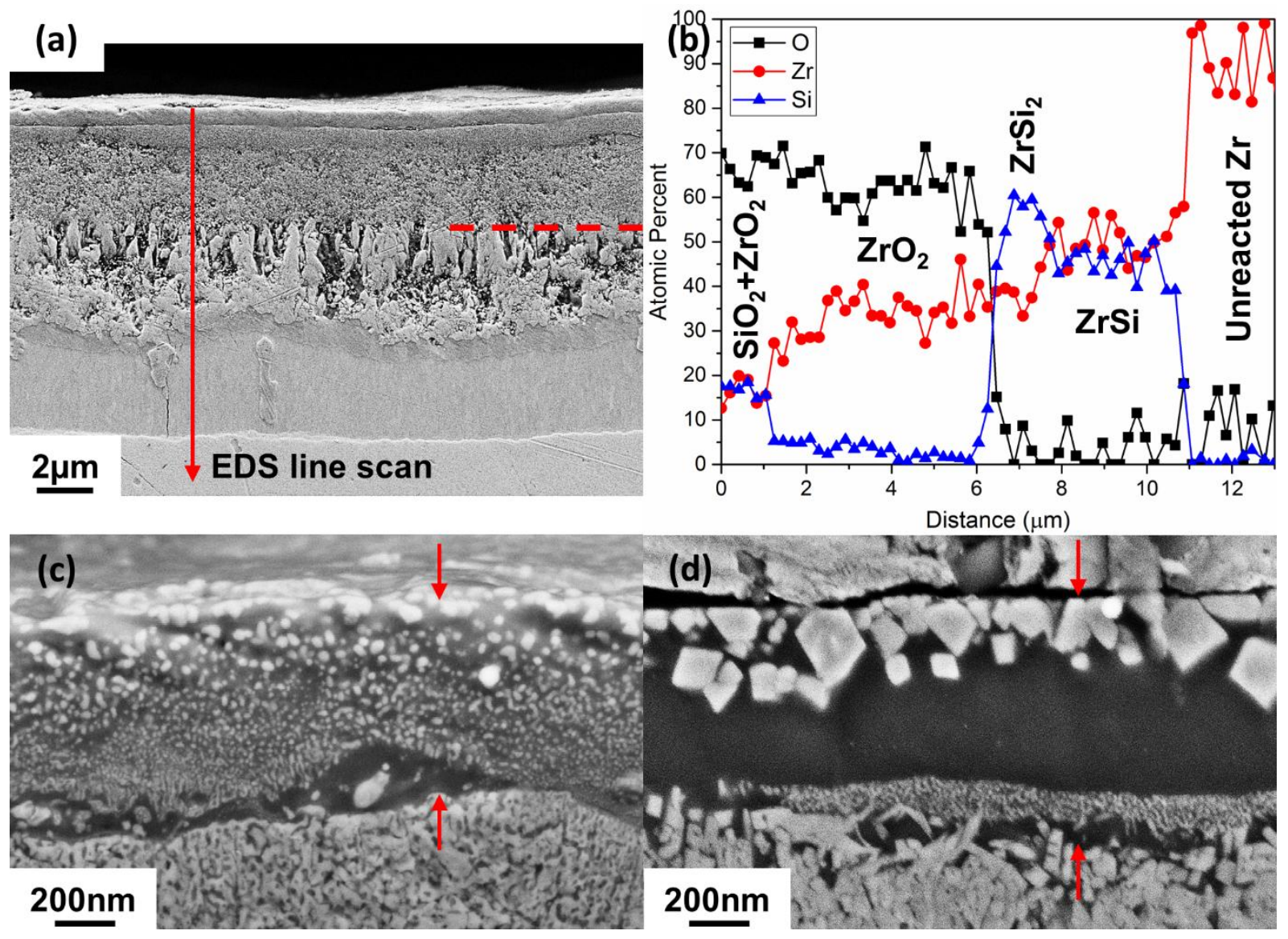

FIG 10 